\title{
“All These Nouns Together Just Don't Make Sense!": An Investigation of EAP Students' Challenges with Complex Noun Phrases in First-Year College-Level Textbooks
}

\author{
Dmitri Priven \\ Algonquin College
}

\begin{abstract}
Complex noun phrases (CNP) are a major vehicle of academic written discourse (Halliday, 1988; 2004). However, in spite of the view that they pose significant challenges to English language learners, they are often overlooked in preparatory English for Academic Purposes (EAP) programs. This mixed methods study aims to investigate to what extent CNP present syntactic parsing challenges for upper-level college EAP students, and whether there is a perceived need for direct instruction in CNP in EAP programs. A special CNP proficiency test was administered to 70 upper-level Ontario college EAP students and a native speaker comparator group, and the results were compared with those obtained from interviews with seven of the test-takers. The results obtained from the statistical analyses and the interviews indicate that CNP are challenging to parse for upper-level EAP students and that direct instruction in CNP may be beneficial for improving their reading comprehension. Some teaching implications of the findings are also addressed.
\end{abstract}

\section{Resumé}

Les groupes nominaux complexes (GNC) sont un vecteur important du discours écrit universitaire (Halliday, 1988; 2004). Cependant, bien qu'on admette les difficultés qu'ils posent aux apprenant.e.s d'anglais, les GNC sont souvent peu pris en compte par les programmes préparatoires d'anglais sur objectifs universitaires (English for Academic Purposes ou EAP). Cette étude à méthodologie mixte vise à déterminer dans quelle mesure a) les GNC présentent des défis d'analyse syntaxique pour les étudiant.e.s de l'enseignement collégial postsecondaire inscrit.e.s à des cours EAP avancés, et b) un enseignement explicite des GNC est perçu comme nécessaire. Un test de compétence spécifique aux GNC a été administré à 70 étudiant.e.s de cours EAP avancés d'un collège de l'Ontario et à un groupe comparatif composé de locuteurs natifs; les résultats au test ont été triangulés par le moyen d'entretiens avec sept participants. Les résultats obtenus à partir des analyses statistiques des tests et des entretiens indiquent que les GNC sont difficiles à analyser pour les étudiant.e.s des cours EAP avancés, et que l'enseignement explicite des GNC pourrait permettre d'améliorer leur compréhension en lecture. Des pistes pédagogiques découlant des résultats sont également abordées. 


\section{“All These Nouns Together Just Don't Make Sense!": An Investigation of EAP Students' Challenges with Complex Noun Phrases in First-Year College-Level Textbooks}

The challenges experienced by English language learners (ELLs) when dealing with academic discourse have been thoroughly documented over the past forty years (for a summary, see De Chazal, 2014). One such challenge is the acquisition of specific features of complexity within academic English by ELLs (Schleppegrell, 2004). This complexity is aptly captured by Zwiers (2006):

Much more complex than a list of words and phrases to memorize, academic language embodies the cognitive, linguistic, cultural, and discipline-specific features of discourse found in school and beyond - in scientific, business, and other technical arenas. This is a double challenge for many students who are learning not only another language but also the academic dialect of that language. Closely related to issues of language are the dimensions of academic thinking: the ways in which experts from various disciplines approach their research and argumentation. (p. 317-318).

ELLs often have to understand and use authentic academic language along with their English-speaking peers in postsecondary institutions all over the English-speaking world. This paper addresses one feature of academic language: complex noun phrases (CNP), defined as phrases where a noun is the head modified by preceding or following lexical items. CNP are a major vehicle of academic written discourse (Halliday, 2004). They constitute the grammatical complexity and lexical density inherent specifically in writing for natural sciences, social sciences, engineering, and commerce at both the secondary and the post-secondary level (Schleppegrell, 2004; Fang, Schleppegrell \& Cox, 2006; Massoud \& Kuipers, 2008; Zwiers, 2008).

Drawing on their academic corpora-based research spanning the past 20 years, Biber and Gray (2016) present a variety of [(modifier) $+\mathrm{N}+$ (modifier)] configurations occurring in academic discourse. These are summarized in Table 1 with sample CNP from Biber and Gray (2016) and from select discipline-specific and English for Academic purposes textbooks (abbreviations related to CNP in the table below and further in the text are mine): 
Table 1

Examples of CNP structures

\begin{tabular}{ll}
\hline \multicolumn{1}{c}{ PRE-MODIFICATION } & \multicolumn{1}{c}{ POST-MODIFICATION } \\
\hline $\begin{array}{l}\text { Nouns - NMod } \\
\text { regression analysis; } \\
\text { mean plasma glucose values }\end{array}$ & $\begin{array}{l}\text { Prepositional phrases - PPMod } \\
\text { the utilization of such devices for social } \\
\text { purposes; } \\
\text { a focus on measures of student outcomes; } \\
\text { methods of assessing error }\end{array}$ \\
\hline $\begin{array}{l}\text { Attributive adjectives - AMod } \\
\text { XML-based modelling; } \\
\text { basin-distributed temperature }\end{array}$ & $\begin{array}{l}\text { Adjective clauses and reduced adjective } \\
\text { clauses/participial phrases - CLMod } \\
\text { levels that have not been seen for millions } \\
\text { of years; } \\
\text { changes preserved in sedimentary rocks }\end{array}$ \\
\hline
\end{tabular}

Gerund Phrase - GerP

Increasing GDP among higher-income countries [resulted in]; including poor countries [showed positive correlation between GDP and happiness]

COMBINED PRE- AND POST-MODIFICATION - various combinations of NMod, PPMod, AMod, CLMod, GerP

Noun + prepositional phrase - NMod + PP Mod

The patterns of human population growth

Prepositional phrase + attributive adjective - PPMod + AMod

The effects of ozone-depleting compounds

Prepositions phrase + noun + clause - PPMod + NMod + CLMod

No evidence of a satiation point beyond which wealthier countries have further increases in subjective well-being

For the purposes of this study, I chose to focus on the NMod, PPMod, and CLMod types, and combinations thereof, as they present special processing challenges for ELLs due to their semantic (NMod) and syntactic (PPMod, CLMod) complexity. This choice is supported by research by Biber, Gray, and Poonpon $(2011 ; 2013)$, who present a developmental sequence of grammatical complexity features in academic English and confirm through their corpus work that CNP are acquired much later in L2 than finite complement clauses in the development of academic language. In this developmental sequence, CLMod (nonfinite relative clauses) occur fifth last, NMod fourth last, and PPMod (depending on the complexity of embedding of PP within the higher NP) either third last or very last. I personally found this hierarchy of difficulty somewhat surprising, given the potential semantic obscurity of the NMod type, which will be outlined below. My preliminary hypothesis based on my own teaching experience in EAP was that the NMod type would be more challenging than the other CNP types. While the NMod type of CNP are not particularly syntactically complex, they present an additional level of processing challenge based on the semantic and predicative relations between the head and its modifiers, with potentially complex semantic hierarchies. Table 2 presents only the $\mathrm{N}+\mathrm{N}$ configurations. 
Table 2

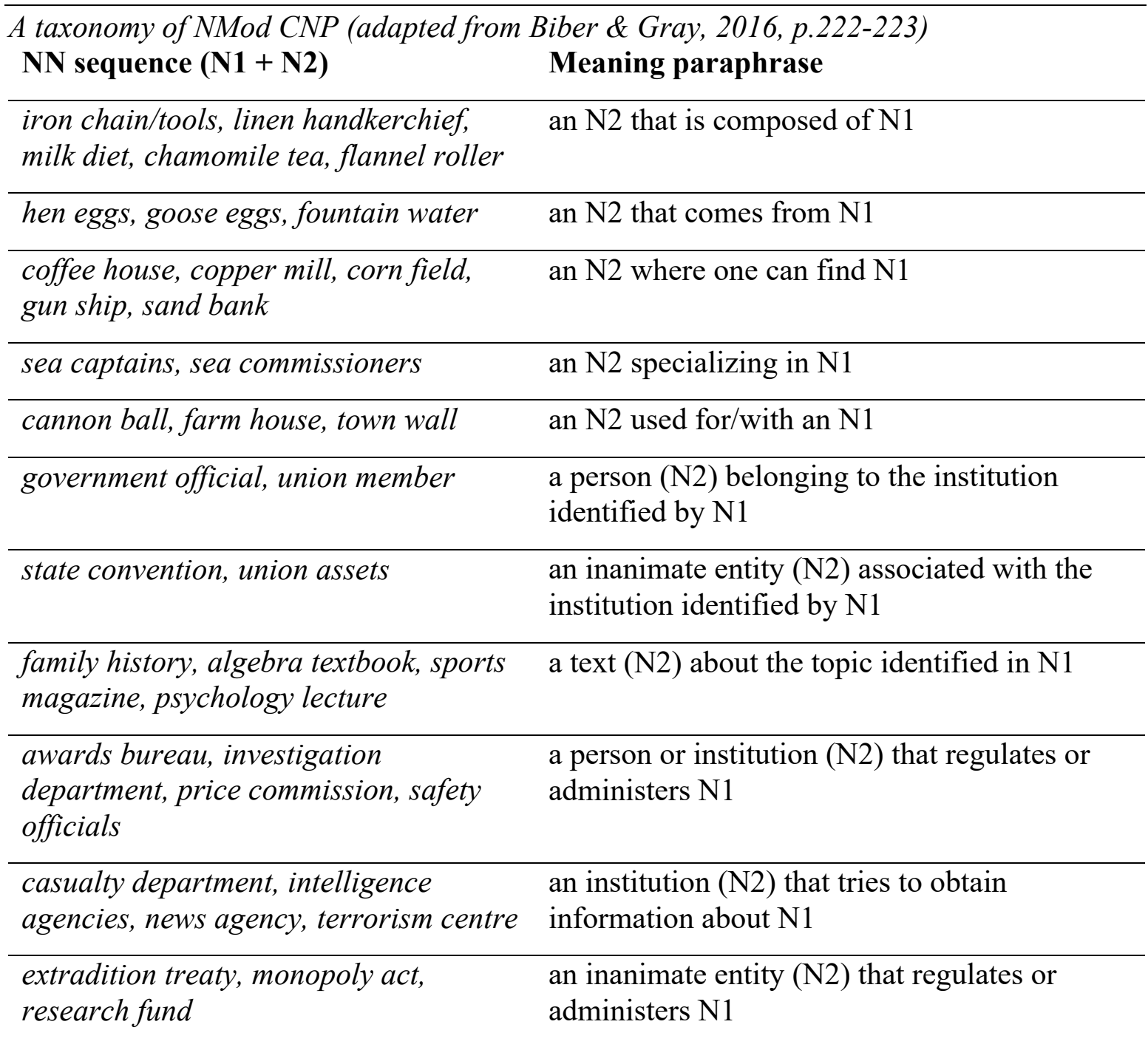

Going beyond the $\mathrm{N}+\mathrm{N}$ configurations of NMod, there are increasing levels of complexity within this category based on the number of modifiers. Trimble (1985, p. 133) classifies them as:

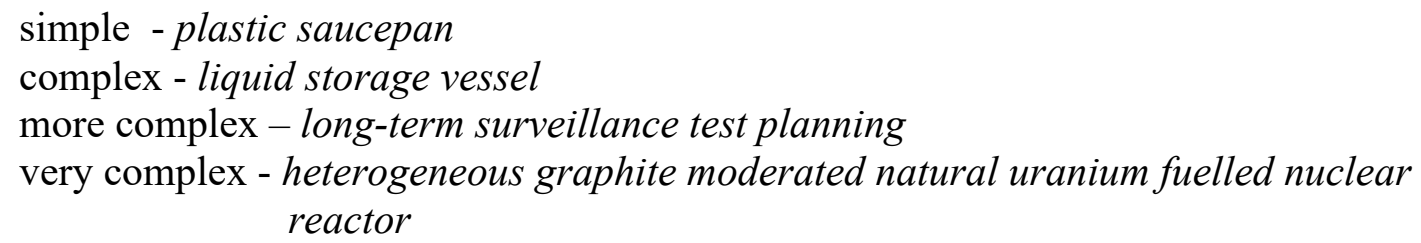

Similarly to Trimble (1985), Manerko (2000, p. 61) presents an elaborate onomasiological classification of the N+ NMod-type CNP based on the level of complexity of both the head and the modifier, specific to military terminology: 
simple onomasiological basis - bacteriological bomb vehicle compound onomasiological basis - carrier-based attack bomber complex onomasiological basis - time of arrival measurement equipment guided bomb

Lexical density in such CNP is based on predicative relationship between the head and its modifiers, which needs to be considered by ELL readers in order to successfully process them (Table 3 adapted from Manerko, 2000, p. 64-65):

Table 3

An onomasiological taxonomy of NMod CNP (adapted from Manerko, 2000, p. 64-65)

\begin{tabular}{ll}
\hline $\begin{array}{l}\text { Types of predicative relations between } \\
\text { head and modifiers }\end{array}$ & Example CNP \\
\hline BE & remote control robot vehicle \\
\hline BE USED FOR OPERATING & engineer squad vehicle \\
\hline BE MADE OF & multicore fiber cable \\
\hline BE PUT IN & decontamination pack set \\
\hline BELONG TO & germ warfare projectile \\
\hline BE USED IN & data acquisition unit \\
\hline BE COVERED BY & full-metal jacket bullet \\
\hline BE COMPOSED OF & air-lubricated hull submarine \\
\hline RESEMBLE & Maltese cross mechanism \\
\hline BE CARRIED BY & rocket-propelled parachute flare \\
\hline
\end{tabular}

This proposed hierarchy of CNP processing difficulty informs one of the research sub-questions below (S3).

However, despite their lexicogrammatical complexity, CNP are hitherto virtually an uncharted territory in the teaching practice in preparatory EAP programs designed to improve academic English listening, speaking, reading, and writing skills and to prepare international college and university students for undergraduate programs in the Englishspeaking world (Maxwell-Reid, 2015; Ward, 2007). A thorough review of commercially available textbooks published in North America did not yield any mentioning of CNP or complex nominals (see Beatty, 2015; Oshima \& Hogue, 2014, Rosenberg, 2015; Williams, 2013, among others). In my personal experience in various Canadian EAP programs over the past 20 years, I have yet to encounter any systematic pedagogical treatment of CNP in reading or writing curricula. Absence of CNP is further evidenced by Biber, Gray, and Poonpon (2013) in their review of advanced grammar textbooks. The only textbooks found that focus on noun phrases (but not CNP) explicitly are by Marshall (2018). However, there is a significant body of research that acknowledges the challenges of CNP for EAP students (Chan, 2004; Herczeg \& Himelfarb, 2008; Maxwell-Reid, 2015; Montero, 1997). For example, syntactic interference from L1 may be a factor in the processing of CNP for Mandarin-speaker (Chan, 2004) and Spanish-speaker (Carrio Pastor, 2008; Herczeg \& Himelfarb, 2008) ELLs. The nominal pre-modifier type CNP are right-headed in English, which means that the head is the rightmost element and the modifiers are always in preposition to the left of the head. Cross-linguistically, the genitive and attributive $\mathrm{N}_{\mathrm{x}}+\mathrm{N}_{\mathrm{y}}$ 
configurations can be realized as either right-headed (German, Bashkir, Turkish, and Nivkh), left-headed (Mandarin Chinese, Indonesian, French, Arabic, Spanish, Loniu, and Chalcatongo Mixtec), or both (Russian) (Dryer, 2007). Rijkoff (2002) also presents significant cross-linguistic variation in nominal post-modification.

CNP-headedness is not the only challenge for ELLs inherent in processing them. Due to their lexical density and complex syntactic structure, processing CNP often involves simultaneous use of lexical access (understanding discrete lexical items) and syntactic parsing abilities (understanding grammar), the two lower-level reading processing skills (Grabe \& Stoller, 2002) acting synergistically and often in a compensatory manner in L2 reading (Bernhardt, 2011). There seems to be an iterative interactive process between the two lower processing skills and the higher-level processing skill of semantic proposition formation when processing CNP. The theoretical models that have been proposed to account for the NMod type CNP processing algorithms by native speakers of English make use of lexical access and syntactic parsing in tandem. Wisniewski (1997) proposes a multistage processing mechanism that is engaged when processing an NMod type CNP: comparison between head and modifier, cue validity assessment, and category validity assessment. As an algorithm, this involves assessing the frequency of associations between the head and the modifier, calculating coherence of potential interpretations of the relationships between them, and finally assessing the fit of the resulting interpretation within the overall propositional context. Gagné and Shoben (1997) propose another model of processing of the same type of CNP based on the frequency of associations between the head and the modifiers: the Competition Among Relations in Nominals (CARIN) model. In this model, the initial choice of interpretation depends on the frequency of associations between the head and its modifiers determined by the reader. This choice may be then revised if the interpretation by the reader does not make sense in the context of the sentence or in a larger textual context. In addition, identifying the syntactic or thematic role of a CNP (Warren \& Gibson, 2005) and finding their attachment to a predicate (Gordon, Hendrick, Johnson, \& Lee, 2006) are factors contributing to their successful processing and interpretation. As we can see, in these models lexical access and syntactic parsing dovetail, and syntactic parsing is impossible without lexical access. These theoretical considerations again speak to the processing complexity associated specifically with the NMod type, and precipitate my research sub-question S3, which I will address both quantitatively and qualitatively.

While both syntactic parsing ability and lexical knowledge have been cited among the highest predictors of successful reading comprehension in L2 (Jeon \& Yamashita, 2014), vocabulary knowledge and resulting lexical access ability figure as a stronger predictor of L2 reading comprehension than syntactic parsing ability specifically at higher proficiency levels and in EAP contexts (Aryadoust \& Baghaei, 2016; Nassaji, 2003; Zhang, 2012). In fact, Droop and Verhoeven (2003) note that the higher the level of L2 proficiency, the bigger the influence of vocabulary over grammatical knowledge on reading comprehension success. Another top predictor of L2 reading comprehension success related to vocabulary knowledge is topic familiarity and discipline-specific knowledge (Alderson, 2000), which usually translates into knowledge of specialized vocabulary, especially cognates and English-based common academic vocabulary core. However, as Usó-Juan (2006) points out, discipline-specific knowledge is only a factor overriding general language proficiency at lower levels; at higher levels, general L2 proficiency predicts reading comprehension success two to three times better than specialized knowledge. In 
light of this, it would be interesting to find whether discipline-specific knowledge translated into better processing ability of CNP, which leads to my research sub-question S2.

There is also a significant body of research amassed over the past 30 years that speaks to the benefit of direct instruction of the grammatical features of a text for reading comprehension purposes (Hudson, 1991; Sharwood Smith, 1993; Walters, 2006). Furthermore, over the past decade-and-a-half, a number of noticing-based and SFLinformed approaches have emerged specifically in teaching CNP as genre features of academic texts (Liardét, 2016; Parkinson, 2015; Pritchard \& Nasr, 2004; Ward, 2007). Specifically, Liardét (2016) speaks to the limitations in the use of grammatical metaphors (which could be classified as CNP) among ELL university students in Australia without explicit instruction on the writing devices based on them, such as anaphoric reconstrual, nominal group elaboration, and cause and effect metaphorical networks. In this regard, it would be interesting to see whether in a Canadian EAP context the facility with CNP may emerge thanks to mere exposure to pseudo-academic texts, without any targeted teaching of them. This leads to my research sub-question S1.

This paper presents the results of a pilot study for a larger project envisioning a CNP-based teaching intervention in a bridging-level college-based preparatory EAP program. This mixed method study attempts to categorize and measure college EAP students' specific challenges in syntactic parsing of CNP and perceived usefulness of explicit instruction on the grammatical complexity within CNP in upper-level academic reading courses in preparatory non-credit EAP programs. Specifically, it aims to address the following question: to what extent is processing and comprehension of CNP challenging for upper-level college EAP students? Within this research question, of special interest are the following three sub-questions:

S1) To what extent is length of stay in an EAP program a factor in successful syntactic parsing of CNP?

S2) To what extent is relative familiarity with the subject matter a factor in successful syntactic parsing of CNP?

S3) What types of CNP present the biggest syntactic parsing challenges?

\section{Method}

\section{Study design}

In order to address the research question and the sub-questions, I conducted a mixed method study integrating quantitative and qualitative data analyses in a convergent design (Creswell, 2015). This type of design involves collecting quantitative and qualitative data separately and then merging the results. The convergent design lends itself well for the purposes of this study because the extent of EAP students' CNP comprehension challenges in reading comprehension (or lack thereof) can be assessed through quantitative measures and probed further through a qualitative component.

For the quantitative component of this study, the participants took part in a specially designed CNP comprehension test (see Description of test section). The tests scores were analyzed statistically and informed the semi-structured interview protocol, which served as the qualitative component of the study. 


\section{Participants}

For the purposes of this study, a sample of 70 full-time students was recruited from several sections of an upper-level non-credit pathway EAP course at a large provincial applied arts and technology college in a major urban centre in Ontario, Canada. This is the highest level in the preparatory EAP program, upon the passing of which, students gain entry into any post-secondary program at the College. The EAP curriculum at this college covers a wide range of academic skills, both receptive and productive, in a non-disciplinespecific way. The overall English language proficiency at this level corresponds to an IELTS $6-6.5$, or CEFR B 2.2. With the exception of the Cree students in the sample, the participants were either international students or permanent residents of Canada. Their age ranged from 18 to 45 years; they were not educated in English through their primary and secondary school; they had either secondary or tertiary education; some of them were professionals in their home countries. The majority of the students were conditionally accepted into various programs of study at the college, in areas such as nursing, early childhood education, computer programming, interactive media design, business, marketing, and green architecture, among others. Their L1 included Arabic, Bosnian, Mandarin and Cantonese Chinese, Cree, Dari/Farsi, English, French, Japanese, Korean, (Brazilian) Portuguese, Punjabi, Russian, Spanish, Tagalog, and Vietnamese. Their length of stay in the EAP program ranged from 1 to 14 months, which in approximately $85 \%$ of cases corresponded to their length of stay in Canada. The participants were recruited on a voluntary basis by circulating a call for participation. This sample is representative of the demographics in the EAP program where the sample was sourced, and of many similar university and college-based EAP programs across Canada.

\section{The quantitative component}

Description of test. For the quantitative component, since no specific CNP comprehension test had been found in the literature, a specially designed grammatical complexity test (see Figure 1, henceforth the CNP test) was administered to establish the participants' facility in processing CNP in the context of first-year college textbooks. These are the learning resources the students would encounter in their respective college programs upon succeeding in the bridging EAP course. The CNP test consisted of randomly selected short passages from introductory parts of various chapters in ten first-year college textbooks used at the research site, taken from the introductory courses in nursing, psychology, marketing, chemistry, computer science, environmental science, physics, biology, massage therapy, and economics. The choice of these introductory textbooks ensured that the test takers did not need any specialized knowledge to answer the test items.

Each passage included three multiple-choice syntactic parsing tasks based on the underlined sentence constituents (see Figure 1):

1) Identifying the verb in a string consisting of a CNP and a verb, or whether there is a verb following the noun phrase (henceforth VERB ID)

2) Identifying a head noun in a CNP (henceforth NOUN ID)

3) Identifying the correct paraphrase of an underlined CNP (henceforth PARA) 


\section{PSYCHOLOGY - SLEEP PATTERNS (Questions 1-3)}

1 Recent research has shown that REM (Rapid Eye Movement) sleep aids in information

2 processing, helping people sift through daily experiences in order to organize and store in

3 memory information that is relevant to them. Karni (1994) found that research participants

$4 \quad$ learning a new perceptual skill showed an improvement in performance, with no additional

5 practice, 8 to 10 hours later if they had a normal night's sleep or if only their NREM was

6 disturbed. Naps that are long enough to include both slow-wave and REM sleep also appear to

7 enhance learning.

1. What is the verb in the underlined phrase in Lines 1-2?

2. What is the head noun in the underlined phrase in Line 6 ?
a. REM
b. slow-wave
c. sleep
d. wave

3. Which phrase is the closest in meaning to the underlined phrase in Lines 3-4?

a. Participants in the research who are learning a new skill

b. Researching participants who are learning a new skill

c. Researchers who are learning a new skills

d. Participating researchers who are learning a new skill

Figure 1. Sample test task (adapted from Wood, 2014).

The front page of the test contained some instructions on nouns and verbs and on the term head noun so that potential lack of metalinguistic awareness on the part of some of the otherwise advanced students did not influence their responses.

The types of CNP included in the test were:

- $\quad$ pre-modified CNP, including NMod (tissue damage) and AMod + NMod (the cardiac output drop),

- $\quad$ post-modified CNP, including PPMod (the body's system of defenses against infectious disease), and

- combined pre-modification and post-modification: e.g., NMod + CLMod (research participants learning a new perceptual skill).

All in all, there were 28 test items: 9 NOUN ID items, 10 VERB ID items, and 9 PARA items. Each test item was worth one point. The test was scored out of 28; the raw score was then converted into a percentage.

Test validation. The procedures below outline the theoretical validation considerations in compiling the original CNP proficiency test.

To operationalize the construct of syntactic parsing ability in the CNP test, I decided to make the test items as decontextualized and discrete as possible. Urquhart \& Weir (1998) urge to construct measurement tools meant to assess syntactic parsing ability with as little communicative focus as possible, to measure the syntactic parsing ability without contamination from other reading comprehension skills/strategies (e.g., relying on 
contextual clues). However, I decided against presenting completely unconnected sentences to ensure the authenticity/face validity of the test for the participants, hence the threesentence excerpts from first-year college textbooks. The brevity of the excerpts would prevent the participants from relying on any meaning that would have been possible to extract by relying on contextual clues available in a larger reading passage. In addition, it did not seem likely that the participants would be able to process any of the test items as lexical rather than syntactic - the NOUN ID and the VERB ID items may have the same word form, and in the PARA items much of the lexicon is the same in the stem as in the distractors (see Figure 1).

To ensure further test item validity, as recommended by Urquhart and Weir (1998), the first draft of the CNP test was presented to a panel of five EAP instructors for their feedback on whether the items are lexically or syntactically based. Only the items deemed syntactic by all five judges were included in the final version of the CNP test. In order to further ensure the validity of the test, it was also administered to a control group of 15 native English-speaking first-year college students.

The following considerations determined the shape of the test items in relation to the complexity inherent in CNP. Comprehension of CNP by ELLs in academic contexts has been measured through test tasks involving identification of the head noun (NOUN ID task in the CNP test), pre- and post-modifiers, and comprehension questions based on paraphrases (PARA task in the CNP test) (Benassi et al., 2011), and through having ELLs write sequences of CNP immediately after reading them (Jullian, 2002). In addition, it seemed that a task involving verb identification (VERB ID task in the CNP test) would also be appropriate since subject and verb parsing are often seen as a measure of sentence processing and proposition formation success (Grabe \& Stoller, 2002).

After the test was administered and results collected, an item analysis was conducted, which determined that only one test item had a $\mathrm{p}<20 \%$ on the item difficulty scale. This item was not included in the statistical analyses.

To determine the test's internal consistency reliability, the relationship between mean test scores on NOUN ID, VERB ID, and PARA tasks for each participant and their mean overall test scores was investigated using Pearson product-moment correlation coefficient. There was a strong, positive correlation between the scores for each type of task and the overall test scores (Table 2).

Table 4

Correlations between types of test tasks and overall test scores

\begin{tabular}{lll}
\hline Type of task & Pearson's R & P \\
\hline NOUN ID & 0.7025 & $<0.00001$ \\
\hline VERB ID & 0.7133 & $<0.00001$ \\
\hline PARA & 0.5817 & $<0.00001$ \\
\hline
\end{tabular}

The test's internal consistency was also measured using the Kuder-Richardson's reliability coefficient (the KR-20 test). For this test, the score consistency was measured for the two most common type of CNP included in the test (Table 3). According to the KR-20 values (higher than the cut-off 0.6 ), the test is considered internally consistent. 
Table 5

Consistency of test scores by CNP type

\begin{tabular}{ll}
\hline Type of CNP & KR 20 value \\
\hline Test overall & 0.687 \\
\hline NMod CNP & 0.615 \\
\hline PPMod CNP & 0.638 \\
\hline Combined CNP & 0.617 \\
\hline
\end{tabular}

Data analysis consisted of various descriptive and correlational statistical operations done with the help of the SPSS 24 statistical package. The findings are discussed below.

\section{The qualitative component}

After the CNP test was administered and scored, seven EAP students were selected as a purposive sample and invited to participate in a 20-minute semi-structured interview. To ensure a demographically rich cross-section of the participants, the selection criteria involved a range of test scores, length of stay in the program, L1, and post-secondary program choices. The interview questions were focused on challenges in academic reading comprehension in the participants' EAP courses, their assessment of the differences between their regular EAP readings and the reading passages in the test, whether or not they have ever been taught CNP directly, their challenges with the different test tasks, and their opinions on direct teaching of CNP in EAP programs (see Appendix A for complete interview protocol). Test results were shared with the students only at the end of the interviews to avoid the test washback effect (Alderson \& Wall, 1993).

Due to a manageable amount of data collected during the interviews, it was possible to manually code during data collection. Upon transcribing the data, I used the structural coding technique (Saldaña, 2016) during the second cycle of coding, which involves coding in accordance with the structure of the interview protocol. The findings are discussed below.

\section{Findings and discussion}

\section{Findings from the quantitative phase}

The data obtained from the quantitative component of the study addresses the extent of the challenges experienced by the participants with syntactic parsing of CNP in first-year college textbooks. Thanks to the diversity within the student sample, I was able to investigate:

1) whether certain types of CNP are significantly more challenging than others

2) whether length of stay in the EAP program is a significant factor in the degree of facility with CNP, and

3) whether relative familiarity with the subject matter is a significant factor in the degree of facility with CNP. 
Overall test performance. The CNP test scores obtained from the participants are presented below as percentages of items answered correctly. Mean CNP test score was $51.8 \%$. Test scores are also presented by most common L1 groups in the sample.

Table 6

Statistical summary of test scores

\begin{tabular}{lll}
\hline Language & n & Mean Score (/100) \\
\hline Total $^{\mathbf{1}}$ & 70 & 51.8 \\
\hline Chinese $^{2}$ & 18 & 56.6 \\
\hline Arabic & 12 & 56.9 \\
\hline Cree & 12 & 43.7 \\
\hline Vietnamese & 7 & 54.5 \\
\hline French & 5 & 55.9 \\
\hline Spanish and Portguese & 5 & 43.1 \\
\hline Control Group & $\mathbf{1 5}$ & $\mathbf{9 7 . 8}$ \\
\hline
\end{tabular}

The CNP test scores obtained from the participants seemed quite low on average: the mean score $(51.8 \%)$ was much lower than the passing mark in a typical EAP program $(70-80 \%)$. While I am not making a claim that the mean score on the CNP test is in any way indicative of or correlated with passing scores of the EAP program the participants were enrolled in, they scored considerably lower than the control group - English native speakers sampled from various first-year college programs, roughly corresponding to the range of topics on the CNP test. Many of the students scored lower than $50 \%$.

Table 7 represents the participants' performance on each of the three test items. Not surprisingly, NOUN ID and PARA turned out to be the more challenging tasks: Montero (1997) speaks to the challenges ELL experience in locating the head of CNP, and, related to this, coming up with the correct paraphrase based on how the modifier relates to the head.

Table 7

Statistical summary of text scores

\begin{tabular}{ll}
\hline Test item & Mean score $(/ \mathbf{1 0 0})$ \\
\hline VERB ID & 65 \\
\hline NOUN ID & 34 \\
\hline PARA & 55 \\
\hline
\end{tabular}

Challenges with the types of CNP. As far as the three major CNP types that the test included - pre-modified, post-modified, and combinations of pre- and post-modified items — below are the average test scores. 
Table 8

Test scores by CNP type

\begin{tabular}{ll}
\hline CNP types & $\begin{array}{l}\text { Average } \\
\text { scores }\end{array}$ \\
\hline Pre-modified - NMod, AMod & $60 \%$ \\
\hline Post-modified - PPMod, CLMod & $52 \%$ \\
\hline Combination of pre-modified and post-modified - NMod + CLMod, & $44 \%$ \\
NMod + PPMod & \\
\hline
\end{tabular}

The two most challenging CNP types for the test takers were the combined and the post-modified types, with the former proving to be even more challenging than the latter (44\% vs. 52\% success rate respectively), and with post-modified CNP still more challenging than the pre-modified ones ( $52 \%$ vs. $60 \%$ success rate respectively). For example, the participants were more likely to have difficulty with parsing a phrase like the body's system of defenses against infectious disease compared to a phrase like data storage reliability. This is not a surprising finding due to the sheer length of some of PPMod and combined types of CNP in the test and the multiple embedding involved in the relationship between the higher CNP and the embedded prepositional phrase (e.g., a high degree of influence within their peer group). On the other hand, it seems that the other common type of CNP, NMod, also seems somewhat challenging. The participants also commented on that in the interviews: the modifying nouns strung together before the modified head noun may create a multitude of potential meanings. In fact, as was pointed out previously, Biber and Gray (2016) cite up to 15 different semantic configurations within the CNP formed with nominal pre-modifiers. The title of this paper "All these nouns together just don't make sense!" is taken from one of the interviews and speaks to this decoding challenge. For example, the phrase the cardiac output drop was incorrectly interpreted as either cardiac decrease in output, drop in output cardiac, or output of cardiac drop by many of the participants.

Lengths of stay in EAP program and degree of facility with CNP. The relationship between the participants' length of stay in the EAP program (as reported by the participants in the test) and their facility with the CNP was investigated using Spearman's rank-order correlation coefficient. There was a strong, negative correlation between the two variables $(\rho=-0.09804, n=70, p=0.42288)$. This means that length of stay in the EAP program is not positively correlated with higher scores on the CNP test. Length of stay in the EAP program seems to be a robust variable for our purposes because of the rigorous placement testing procedures in the program researched. This finding is not at all surprising since, as has already been mentioned, CNP do not receive any special attention in the EAP program studied. This means that the amount of exposure to academic reading within the program alone, without direct focus on CNP, does not guarantee success in parsing the CNP containing advanced scientific terminology. There were a few students in the sample who had been in the EAP program for 12 to 14 months, and were doing quite well in the EAP program and about to graduate, yet their CNP test scores were quite low. This finding is in line with the general consensus in reading comprehension research that direct focus on bottom-up processing strategies (not just on top-down ones, as is very often practiced in EAP programs) leads to better reading comprehension overall (Moskovsky et al., 2015). 
Relative familiarity with the subject matter and the degree of facility with CNP. The relationship between the participants' relative familiarity with the subject matter used in the test (as extrapolated from their declared program of study; the assumption here was that a participant's declared program of study at the college after EAP was in line with their professional interests, which may have facilitated their reading comprehension in the chosen field of study), and their facility with the CNP (as measured by the CNP test) was investigated using Pearson product-moment correlation coefficient. Of the 70 participants, there were 43 who either had a declared program of study or whose program of study matched the textbook disciplines selected for the test. There was a negative correlation between the two variables $(r=0.3034, n=43, p<0.01)$, with higher scores on the test items related to the participants' chosen program of study than the average test scores appearing in only $48 \%$ of cases. In fact, in about $30 \%$ of the cases the scores on the items related to the declared programs of study were significantly lower than the average test scores (by 20\%). It is concluded, therefore, that the participants' relative familiarity with the subject matter had no direct bearing on their performance on CNP parsing tasks. This finding speaks to the fact that specific bottom-up processing skills are most likely required for CNP processing success. These findings are in line with the results of several studies investigating the relationship between discipline-specific knowledge and general L2 proficiency as success factors in reading comprehension in EAP. The consensus is that English language proficiency level is a better predictor of an EAP reading level than discipline-related knowledge at an intermediate to advanced level of proficiency (Clapham, 1996; Mohammed \& Swales, 1984; Ridgway, 1997; Usó-Juan, 2006), which is the level of proficiency of this study's participants.

\section{Findings from the qualitative phase}

Based on the data collected during the semi-structured interviews following the CNP test, a few common themes emerged. All participants found the language level in the test (extracts from first-year college textbooks from various disciplines) quite challenging compared to their upper-level EAP reading materials. When probed to comment on the specific challenges in the CNP test, all participants responded that they are due to the more specific terminology that is hard to understand because it is expressed through "layers and layers of nouns; they are so hard to get through sometimes" $\left(\mathrm{Omar}^{3}\right)$. "All these nouns together just don't make sense!" was an apt comment from Rick, whose score was midrange. Some of the participants mentioned how condensed the information seemed in the textbook samples compared to their EAP readings. Many of the participants were unaware of the level of complexity of English in the first-year college textbooks because they had never been exposed to this type of literature in English. In fact, a few of them reported the shock they experienced when they had seen the first textbook sample in the test because it was so different from their usual EAP reading materials in terms of the amount of terminology. This finding is echoed in Miller (2010), who found that "the ESL textbooks are providing students neither the exposure to the range of academic vocabulary nor the number of encounters with academic vocabulary that they may need to develop successful comprehension of university textbooks" (p.39), and Atai and Shoja (2011), who found a complete curricular misalignment between the preparatory English for Specific 
Academic Purposes (ESAP) program and the demands of both undergraduate and graduate courses taught in English in Iran.

Related to the findings in Miller (2010) and Atai and Shoja (2011) above was the theme of working with discipline-specific materials in preparatory EAP courses, which emerged as an offshoot of the question on the challenges in the CNP test. The participants all commented that many of the complex concepts they saw expressed through CNP are discipline-specific terms, and suspected there is a plethora of them in college textbooks. They feared it would be difficult to get through all this new vocabulary to keep up with the coursework in the programs they chose. Several of the participants spoke of the importance of designing discipline-specific EAP materials so that some of this new terminology could be tackled in their preparatory EAP courses. It is noteworthy that many college- and university-based EAP programs, notably in Australia (Fenton-Smith, Humphreys, Walkinshaw, Michael \& Lobo, 2017), have piloted the implementation of disciplinespecific EAP streams (e.g., business, engineering, social sciences) at the preparatory noncredit level, and there are a few programs in Canada that have adopted this approach (Tweedie \& Kim, 2015). However, the majority of EAP programs in Canada do not divide their university-bound students into discipline-specific streams due to budgetary constraints (Languages Canada, personal communication).

As far as their previous exposure to CNP, none of the participants had had explicit instruction in CNP in their EAP classes or as part of their previous education, as the findings on the length of stay in the EAP program suggest. The consensus was that nouns are not addressed at all as a grammatical category in their EAP courses; the focus in the grammar component is on complex sentences and genre conventions for writing purposes, and none of the participants recalled any specific grammar-based activities introduced in their reading courses or before the readings. Some of the participants spoke of the benefit of direct grammar teaching (for reading purposes, among others) - they reported a heavy focus on essay writing conventions but not on complex grammar for reading purposes.

All participants thought it would be good to have direct instruction in CNP as part of the upper-level EAP curriculum; some said that the benefit of these is not only in reading but also for speaking purposes - to integrate more terminology into academic discussions. All participants felt there should be explicit explanation on how the nouns interact together in complex noun configurations and what this entails for the meaning of CNP.

\section{Pedagogical implications}

The test scores, as well as the findings from the quantitative stage of this study, are interpreted as an indication of the participants' lack of exposure to and awareness of CNP as a distinct grammatical construct, and the resulting parsing challenges. This is also supported by their comments from the interviews. This evident processing/parsing challenge associated with at least the three types of CNP included in the CNP test, along with the participants' comments, speak to the potential need to explicitly address the complexity within CNP for reading comprehension purposes in academic ESL teaching contexts. The fact that PPMod, NMod, and combined pre- and post-modified CNP were rather challenging to decode may mean that special emphasis needs to be placed on explaining the potential relationships between the modifiers and the head noun in instruction. For example, Fang and Schleppegrell (2008) describe a two-stage adjunct questions approach to parsing lexically dense academic sentences into constituent parts, 
which may help with parsing the multiple layers of phrasal imbedding inherent in the PPMod type of CNP. The second stage of this approach involves posing adjunct questions to focus the learner on the discrete elements within the structure of CNP. For example, in the general CNP structure they present (Premodifier + Head + Postmodifier) the questions Which one? and What kind? are mapped onto premodifiers, the questions Where is it? and Which one? onto postmodifiers, and the question What is the noun phrase about? onto the head.

It is worth noting a certain discrepancy between the perceived need for instruction in discipline-specific language (as evident from the qualitative findings) and the lack of correlation between discipline-specific knowledge and reading comprehension at higher levels of proficiency in L2 (Usó-Juan, 2006). It seems that the participants, all of whom were at the level of English proficiency almost acceptable for entry into college programs of study, felt disadvantaged by lack of instruction in discipline-specific terminology in their EAP courses. I believe that explicit instruction on the syntactic parsing strategies applicable to CNP generically may provide the necessary syntactic foundation to compensate for the lack of discipline-specific terminology knowledge that the participants in this study felt overwhelmed with. For example, rather than teaching the lexical chunk/collocation data storage reliability, which may have limited application in a generic EAP course, as a discipline-specific term as presented in Ward (2007), an instructor could unpack the syntactic logic behind its construction as a CNP expressed as an NMod in line with one of the genitive semantic configurations in Biber and Gray (2016). Such syntactic approaches are mentioned in Benassi et al. (2011), Pritchard and Nasr (2004), and Woodward-Kron (2008). For example, Pritchard and Nasr (2004) present unchaining nominal compounds as one of the language-focused intervention areas in a reading EAP for Engineering course in an Egyptian university. The teaching tools described to present specifically the NMod type of CNP were identifying headwords, backforming pre-modified CNP to genitive PP, paraphrasing CNP using relative clauses, and guessing CNP from context.

Another potential teaching implication arising from this study concerns explicit teaching of CNP as a syntactic parsing process/strategy in academic reading comprehension. Since there seems to be a lack of transfer of syntactic processing strategies from L1 (especially from L1s that are syntactically different from English (Felser et al., [2003]; Papadopoulou \& Clahsen, [2003]), the internal structure of various types of CNP can be taught to EAP students either inductively or deductively and this knowledge can then be operationalized as a skill in level-appropriate practice reading comprehension passages and then in authentic academic texts. This strategy could also become a compensatory reading strategy if the lexical access/word recognition process - another lower-level reading process (Grabe \& Stoller, 2002) - does not yield results (e.g., an ELL stumbles on a word he/she does not know).

Based on the participants' challenges in identifying the correct paraphrase of the target CNP (55\% success rate on the CNP test), it could be hypothesized that instruction in and practice with paraphrasing strategies could help in understanding them. Alderson (2000) and Purpura (1997) cite paraphrasing as a reading comprehension success indicator and a strategy, respectively. In his mixed-methods study based on an experimental teaching intervention he designed for an ELL high-school science class, Lee (2018) used in-text simplified paraphrases of academic CNP to draw his students' attention to the textual resources available to figure out the meaning of unfamiliar concepts expressed as CNP. Lee 
(2018) claims that due to the ample practice with paraphrasing in his intervention, his students became more efficient at processing CNP, and as a result, more fluent readers.

In contrast to the approaches to teaching syntactic parsing strategies applicable to generic EAP programs, Systemic Functional Linguistics (SFL) informed approaches typically involve discipline-specific EAP programs. SFL-informed pedagogy - for example, genre-based pedagogy (Derewianka, 2003; Rose \& Martin, 2012) - typically entails teaching interventions that raise language learners' awareness about the close and immediate relationship between the form and the function of grammatical items. A concrete genre-based teaching intervention involving CNP is cited in Schall-Leckrone (2017), who suggests a teaching approach for a sheltered ELL secondary history class she observed. She presents CNP expressed as nominalization embedded within cause-and-effect formulas that she considers genre-defining in history discourse. For example, the students are given the explanation that in the sentence [The Mongols' invasion] led to [the destruction of the Caliph's palace and mosques] the second CNP - a PPMod type - expresses the effect. In a similar vein, Massoud and Kuipers (2008) treat teaching CNP used in scientific discourse explicitly to post-secondary EAP students as a way of initiating them into the community of practice (English-speaking scientists) and helping them to develop their identities as knowledge-makers.

\section{Generalizability of findings, limitations, and areas for further research}

While each college-based EAP program is unique and may present differences in student demographics, there are certain demographic features within the sample surveyed here that make the findings generalizable to similar non-credit college-based EAP programs in Canada that are based on non-discipline curricula, and potentially elsewhere in the English-speaking world where such programs exist. As was previously mentioned, with the exception of the Cree students, the participants were ESL/EAL students in a college pathway EAP course, ranging in age from 18 to 45 years, either international students or permanent residents of Canada, not educated in English-medium programs through their primary and secondary school. This is a typical cross-section of the EAP student population in Canada. Thus, the implications of this study are that CNP may be a challenge for EAP students entering various college-based programs of study in Canada regardless of their length of stay in the EAP program, their L1, or their chosen academic discipline.

An important incidental finding from the qualitative phase of this study is the importance that the participants attributed to starting to work with discipline-specific reading materials in the EAP program. While this finding is not necessarily generalizable because it comes from a small sample, it is certainly echoed by the calls for further integration of EAP students within mainstream English-language undergraduate programs and their exposure to authentic discipline-specific reading materials with certain pedagogical adjustments and accommodations (Melles, Millar, Morton \& Fegan, 2005; Storch, Morton \& Thompson, 2016).

An interesting area for further research is the relationship between the L1 of EAP students and their CNP parsing ability. In this study, CNP test scores are displayed by L1, but due to the uneven L1 sample sizes these scores were not deemed statistically significant. While speakers of Chinese (Mandarin and Cantonese), Arabic, and Cree were well represented ( $n=18,12$, and 12 respectively), the speakers of Vietnamese, French, and Spanish/Portuguese were less numerous ( $n=7,5$, and 5 respectively). A follow-up study 
with equal sample sizes for all L1s represented here would be necessary to further investigate the relationship between L1 and CNP parsing ability.

Another potentially fruitful area of research that remained beyond the scope of this study would be to test whether Shiotsu and Weir's (2007) claim on grammatical competence being an accurate predictor of reading comprehension proficiency applies to CNP. If in fact it does, that would corroborate our argument on the usefulness of explicit instruction of CNP in EAP programs.

To conclude, this study provides yet another argument for a closer look at the potential role of complex noun phrases in academic English (see the quote from Zwiers [2006] in the introduction) and thus their place in the curricula of preparatory EAP programs and courses, in order to facilitate the EAP students' acquisition of this academic genre and their integration into English-speaking academic communities of practice.

Correspondence should be addressed to: Dmitri Priven.

Email: privend@algonquincollege.com

\section{Notes}

${ }^{1}$ Note that speakers of Russian, Bosnian, Tagalog, Farsi/Dari, and Punjabi did not yield statistically significant data $(n>5)$

${ }^{2}$ Mandarin and Cantonese

${ }^{3}$ All participants' names have been altered.

\section{References}

Alderson, J. C. (2000). Assessing reading. Cambridge: Cambridge University Press.

Alderson, J. C., \& Wall, D. (1993). Does washback exist? Applied Linguistics, 14, $116-$ 129.

Aryadoust, V., Baghaei, P. (2016). Does EFL readers' lexical and grammatical knowledge predict their reading ability? Insights from a perceptron artificial neural network study. Educational Assessment, 21, 135-156.

Atai, M.R. \& Shoja, L. (2011). A triangulated study of academic language needs of Iranian students of computer engineering: Are the courses on track? RELC Journal, 42, 305-323.

Beatty, K. (2015). LEAP Intermediate: Reading and Writing. Montreal: Pearson.

Benassi, C.M., Flores, S., Sobrero, M.E., Stefañuk, M.L., Benassi, M.C., \& Mayol, C.E. (2011). The impact of the complex noun phrase in RC of English scientific texts. Tecné, Episteme y Didaxis, 16, 13-20.

Bernhardt, E. B. (2011). Understanding advanced second-language reading. New York: Routledge.

Biber, D. \& Gray, B. (2016). Grammatical complexity in academic English: Linguistic change in writing. Cambridge: Cambridge University Press.

Biber, D., Gray, B., \& Poonpon, K. (2013). Pay attention to the phrasal structures: Going beyond T-units: A response to WeiWei Yang. TESOL Quarterly, 47, 192-201. 
Biber, D., Gray, B., \& Poonpon, K. (2011). Should we use characteristics of conversation to measure grammatical complexity in L2 writing development? TESOL Quarterly, 45, 5-35.

Carrio Pastor, L. (2008). English complex noun phrase interpretation by Spanish learners. RESLA, 21, 27-44.

Chan, A.Y.W. (2004). Noun phrases in Chinese and English: A study of English structural problems encountered by Chinese ESL students in Hong Kong. Language, Culture, and Curriculum, 17, 33-47.

Clapham, C. (1996). The development of IELTS: A study of the effect of background knowledge on reading comprehension. Cambridge: Cambridge University Press.

Creswell, J. W. (2015). A concise introduction to mixed methods research. Los Angeles: Sage.

De Chazal, E. (2014). English for Academic Purposes: A comprehensive overview of EAP and how it is best taught and learnt in a variety of academic contexts. New York: Oxford University Press.

Derewianka, B. (2003). Trends and issues in genre-based approaches. RELC Journal, 34(2), 133-154.

Droop, M., \& Verhoeven, L. (2003). Language proficiency and reading ability in first- and second-language learners. Reading Research Quarterly, 38, 78-103.

Dryer, M.S. (2007). Noun phrases structure. In Shopen, T. (Ed.), Language typology and syntactic description. Volume 2: Complex constructions (2nd ed, pp. 151-205). New York: Cambridge University Press.

Fang, Z., \& Schleppegrell, M. J. (2008). Reading in secondary content areas: A language based pedagogy. Ann Arbor, MI: University of Michigan Press.

Fang, Z., Schleppegrell, M.J., \& Cox, B. (2006). Understanding the language demands of schooling: nouns in academic registers. Journal of Literacy Research, 28, 247-273.

Felser, C., Roberts, L., Gross, R., \& Marinis, T. (2003). The processing of ambiguous sentences by first and second language learners of English. Applied Psycholinguistics, 24, 453-489.

Fenton-Smith, B., Humphreys, P., Walkinshaw, I., Michael, R., \& Lobo, A. (2017). Implementing a university-wide credit-bearing English language enhancement programme: issues emerging from practice. Studies in Higher Education, 42, 463479.

Gagné, C. L, \& Shoben, E. (1997). Influence of thematic relations on the comprehension of modifier-noun combinations. Journal of Experimental Psychology: Learning, Memory, and Cognition, 23, 71-87.

Gordon, P.C., Hendrick, R., Johnson, M., \& Lee, Y. (2006). Similarity-based interference during language comprehension: Evidence from eye tracking during reading. Journal of Experimental Psychology: Learning, Memory, and Cognition, 32, 1304 1321.

Grabe, W, \& Stoller, F. (2002). Teaching and researching reading. Harlow, UK: Pearson. Halliday, M.A.K. (2004). The language of science. Volume 5 in the Collected Works of M.A.K. Halliday. Edited by Webster, J. J. London: Continuum. (Originally published in 1988).

Herczeg, C., \& Himelfarb, R. (2008). Relaciones sémanticos y significado intrínceso de adjetivos y nombres en sintagmas nominales complejos del inglés. Lenguas Modernas, 32, 85-100. 
Hudson, T. (1991). A content comprehension approach to reading English for science and technology. TESOL Quarterly, 25, 77-104.

Jeon, E. H., \& Yamashita, J. (2014). L2 reading comprehension and its correlates: A metaanalysis. Language Learning, 64, 160-212.

Jullian, P. (2002). The reconstruction of Complex Nominal Phrases by Spanish speaking ESL learners, ESP SIG Newsletter, IATEFL.

Lee, K.K. (2018). The comparative effects of three reading interventions on high school ELLs' reading comprehension and fluency. Paper presented at the Canadian Association of Applied Linguistics conference, Regina, May 28, 2018.

Liardét, C. (2016). Grammatical metaphor: Distinguishing success. Journal of English for Academic Purposes, 22, 109-118.

Manerko, L.A. (2000). Yazyk sovremennoy tekhniki: yadro i periferiya [The language of today's technology: Core and periphery]. Ryazan, Russia: ESPU.

Marshall, S. (2018). Grammar for academic purposes: Accuracy and sentence structure. Montreal: Pearson/ERPI.

Massoud, L.A, \& Kuipers, J.C. (2008). Objectification and the inscription of knowledge in science classrooms. Language \& Education, 19, 211-224.

Maxwell-Reid, C. (2015). The role of clausal embedding in the argumentative writing of adolescent learners of English. System, 49, 28-38.

Melles, G., Millar, G., Morton, J., \& Fegan, S. (2005). Credit-based discipline specific English for Academic Purposes programmes in higher education: Revitalizing the profession. Arts and Humanities in Higher Education, 4, 283-303.

Miller, D. (2010). ESL reading textbooks vs. university textbooks: Are we giving our students the input they may need? Journal of English for Academic Purposes, 10, 32-46.

Mohammed, M. A. H., \& Swales, J. M. (1984). Factors affecting the successful reading of technical instruction. Reading in a Foreign Language, 2, 206-217.

Montero, B. (1997). Technical communication: Complex nominals used to express new concepts in scientific English - causes and ambiguity in meaning. The ESPecialist, $17,57-72$.

Moskovsky, C., \& Jiang, G., Libert, A., \& Fagan, S. (2015). Bottom-up or top-down: English as a Foreign Language vocabulary instruction for Chinese university students. TESOL Quarterly, 49, 256-277.

Nassaji, H. (2003). Higher-level and lower-level text processing skills in advanced ESL reading comprehension. Modern Language Journal, 87, 261-276.

Papadopoulou, D., \& Clahsen, H. (2003). Parsing strategies in L1 and L2 sentence processing: A study of relative clause attachment in Greek. Studies in Second Language Acquisition, 24, 501-528.

Parkinson, J. (2015). Noun-noun collocations in learner writing. Journal of English for Academic Purposes, 20, 103-113.

Pritchard, R., \& Nasr, A. (2004). Improving reading performance among Egyptian engineering students: Principles and practice. English for Specific Purposes, 23, 425-445.

Purpura, J. (1997). An analysis of the relationships between test takers' cognitive and metacognitive strategy use and second language test performance. Language Learning, 47, 289-325. 
Ridgway, T. (1997). Thresholds of background knowledge effect in foreign language reading. Reading in a Foreign Language, 11, 151-166.

Rijkoff, J. (2002). The noun phrase. Oxford: Oxford University Press.

Rose, D., \& Martin, J.R. (2012). Learning to write, reading to learn: Genre, knowledge and pedagogy in the Sydney School. London: Equinox.

Rosenberg, M. (2015). Perspectives: Academic reading skills and practice. Toronto: Oxford University Press.

Saldaña, J. (2016). The coding manual for qualitative researchers, $3^{\text {rd }}$ edition. Thousand Oaks, CA; Sage.

Schall-Leckrone, L. (2017). Genre pedagogy: a framework to prepare history teachers to teach language. TESOL Quarterly, 51, 358-382.

Schleppegrell, M.J. (2004). The language of schooling: A functional linguistics perspective. Mahwah, NJ: Lawrence Erlbaum.

Sharwood Smith, M. (1993). Input enhancement in instructed SLA: Theoretical bases. Studies in Second Language Acquisition, 15, 165-179.

Shiotsu, T., \& Weir, C. J. (2007). The relative significance of syntactic knowledge and vocabulary breadth in the prediction of RC test performance. Language Testing, 24, 99-128.

Storch, N., Morton, J., \& Thompson, C. (2016). EAP pedagogy in undergraduate contexts. In Hyland, K. \& Shaw, P. (Eds.), The Routledge handbook of English for Academic Purposes (pp. 477-488). New York: Routledge.

Trimble, L. (1985). English for science and technology: a discourse approach. Cambridge: Cambridge University Press.

Tweedie, G. \& Kim, M. (2015). Student input and curriculum alignment in EAP. Paper presented at the TESL Canada conference, November 29, 2015.

Urquhart, A.H., \& Weir, C.J. (1998). Reading in a second language: Process, product, and practice. New York: Longman.

Usó-Juan, E. (2006). The compensatory nature of discipline-related knowledge and English-language proficiency in reading English for Academic Purposes. The Modern Language Journal, 90, 210-227.

Walters, J. (2006). Methods of teaching inferring meaning from context. RELC Journal, 37 , 176-190.

Ward, J. (2007). Collocation and technicality in EAP engineering. Journal of English for Academic Purposes, 6, 18-35.

Warren, T., \& Gibson, E. (2005). Effects of NP type in reading cleft sentences in English. Language and Cognitive Processes, 20, 751-767.

Williams, J. (2013). LEAP Advanced: Reading and writing. Montreal: Pearson.

Wisniewski, E. J. (1997). Conceptual combination: Possibilities and esthetics. In Ward, T.B., Smith, S.M., \& Vaid, J. (Eds.), Creative thought: An investigation of conceptual structures and processes (pp. 51-81). Washington, DC: American Psychological Association.

Wood, S.E. (2014). The world of psychology, 7th edition. Montreal: Pearson.

Woodward-Kron, R. (2008) More than just jargon - the nature and role of specialist language in learning disciplinary knowledge. Journal of English for Academic Purposes, 7, 234-249. 
Zhang, D. (2012). Vocabulary and grammar knowledge in second language reading comprehension: A structural equation modeling study. Modern Language Journal, $96,558-575$.

Zwiers, J. (2006). Integrating academic language, thinking, and content: Learning scaffolds for non-native speakers in the middle grades. Journal of English for Academic Purposes, 5, 317-332.

Zwiers, J. (2008) Building academic language: Essential practices for content classrooms, grades 5-12. San Francisco, CA: Jossey-Bass. 


\section{Appendix}

Interview Protocol

\begin{tabular}{|c|c|}
\hline QUESTION & COMMENTS \\
\hline $\begin{array}{l}\text { Q1. Background } \\
\text { 1a. Tell me a little bit about your } \\
\text { educational background. } \\
\text { 1b. How long have you studied in } \\
\text { the EAP program? } \\
\text { 1c. Did you have any previous } \\
\text { experience in EAP (and } \\
\text { specifically with reading } \\
\text { academic texts) in your country } \\
\text { before coming to Canada? }\end{array}$ & \\
\hline $\begin{array}{l}\text { Q2. Challenges with academic } \\
\text { reading } \\
\text { 2a. Have you experienced any } \\
\text { challenges in academic reading } \\
\text { comprehension in your EAP } \\
\text { courses? } \\
\text { 2b. How do EAP } 3 \text { readings } \\
\text { compare to the readings on the } \\
\text { test in their level of English? }\end{array}$ & \\
\hline $\begin{array}{l}\text { Q3. Complex Noun Phrases } \\
\text { 3a. What do you know about the } \\
\text { role of nouns in academic } \\
\text { writing? } \\
\text { 3b. Have you ever been taught } \\
\text { complex noun phrases like this } \\
\text { (give example) directly? }\end{array}$ & \\
\hline
\end{tabular}




\section{Q4. Let's go through some of} your answers on the test.

4a. Were the questions on identifying the head noun (like this one __ easy or difficult?

4b. How about the questions on paraphrasing vs identifying the head noun? Identifying the verb?

4c. What makes these types of questions easy/difficult?

\section{Q5. Do you think direct teaching} of the different types of complex noun phrases like you saw on the test would be helpful for your future academic work? If no, why not? If yes, in what way?

Q6: Before we conclude, would you like to add anything else? 